\title{
Deterioration of mechanically ventilated patients in the presence of intra-abdominal hypertension
}

\author{
Ghada Shalaby Khalaf Mahran*1, Amal Ismael Abd El-Hafez ${ }^{1}$, Mostafa Samy Abbas ${ }^{2}$ \\ ${ }^{1}$ Critical Care and Emergency Nursing department, Faculty of Nursing, Assiut University, Assiut, Egypt \\ ${ }^{2}$ Faculty of Medicine, Assiut University, Assiut, Egypt
}

Received: December 13, 2017

DOI: $10.5430 /$ jnep.v8n8p105
Accepted: March 11, 2018

URL: https://doi.org/10.5430/jnep.v8n8p105

\begin{abstract}
Background and objective: Elevated pressure within the cavity of the abdomen is a serious complication that can threat the life of critically ill patients. Thus, there is an intense need to highlight the outcomes of intra-abdominal hypertension (IAH) that can face critical care nurses. Objective: This work aimed to explore the deterioration of mechanical ventilated patients in the presence of IAH.

Methods: Design: A non-randomized prospective study. Procedures: This trial was implemented in trauma and general intensive care in the period between December 2015 and August 2016. The pressure within the abdomen was measured for each patient, three times with 8-hr interval, at the third day of mechanical ventilator (MV). Sepsis-related organ failure assessment score was measured for all patients at first day of admission. All patients who had normal intra-abdominal pressure (IAP) or developed IAH were observed, monitored and evaluated for the clinical outcomes until discharged.

Results: Of the $60 \mathrm{MV}$ patients, $83.3 \%$ developed IAH. Higher mean of MV and stay period among patients with increased pressure within the abdomen (14.04 \pm 10.30 and $16.30 \pm 9.36)$ than normotensive patients $(6.90 \pm 2.80$ and $11.000 \pm 3.77)$ with significant difference $(p=.001)$. Non-survivor had a significantly higher mean IAP than survivor $(23.266 \pm 2.37$ vs. $7.91 \pm 3.17)$ ( $p$ value <.001)

Conclusions: The occurrence of IAH complicated $83.3 \%$ of mechanical ventilated clients in the study period: like longer stay and use of ventilator, and high mortality rate.
\end{abstract}

Key Words: Mechanical ventilation, Intra-abdominal hypertension, Deterioration

\section{INTRODUCTION}

The nurses in the intensive care area are overwhelmed by patients with increased risk who require continuous monitoring in addition to complex care systems. Therefore, nurses have to be able to interpret and handle the objective and subjective information for immediately and aggressive interventions implementation. ${ }^{[1]}$

There is a pressure inside each cavity in the body, the pressure within the cavity of the abdomen is known as intra-abdominal pressure (IAP) which lies between $5 \mathrm{mmHg}$ and $7 \mathrm{mmHg} .{ }^{\text {[2] }}$ When the pressure is sustained or elevated due to pathological causes above $12 \mathrm{mmHg}$, developed to Intra-abdominal hypertension (IAH). ${ }^{[3]} \mathrm{New}$ organ failure or dysfunction with sustained IAP greater than $20 \mathrm{mmHg}$ (with or without abdominal perfusion pressure [APP] $<60 \mathrm{mmHg}$ ) is called abdominal compartment syndrome (ACS). ${ }^{[4,5]}$ This syndrome is responsible for the increase in prevalence of death from $90 \%$ to $100 \%$ if not immediately recognized and treated. ${ }^{[6,7]}$

\footnotetext{
* Correspondence: Ghada Shalaby Khalaf Mahran; Email: ghada.mahran@ nursing.aun.edu.eg; Address: Critical Care and Emergency Nursing Department, Faculty of Nursing, Assiut University, Assiut, Egypt.
} 
Nurses in acute settings need to analyze the driving factors of IAH and ACS. The prediction and care of IAH and ACS are essential for improving the results of health. ${ }^{[8]}$ Disorders of the organ functions, sepsis, last abdominal operation, need for mechanical ventilation with positive end-expiratory pressure (PEEP) or auto-PEEP, have all been reported to increase pressure inside the abdomen. ${ }^{[9]}$

The percentage of IAH in acutely ill patients is documented to be $50 \%,{ }^{[10]}$ of these, $50 \%, 32.1 \%$ develop IAH within their first $24 \mathrm{~h}$ of ICU admission. ${ }^{[11,12]}$ The concept of IAP and its impact on disorders in organ function in patients has significant interest grew. IAH not only affects the abdominal organs-but it affects various organ of the body like the respiratory system, blood dynamics and cerebral perfusion. ${ }^{[6,9,13]}$

The IAP and APP testing are inexpensive and useful tools for diagnosis and detecting complications. Because of the repeated occurrence of IAH and ACS, nurses in critical units must regularly monitor IAP and APP. Nurses in a critical setting play a necessary role to determine IAH and ACS, implement and evaluate interventions. ${ }^{[14]}$

The tasks of the trial were to:

Assess how the elevated IAP affects critically ill patients' outcomes as a period of MV, ICU stay and mortality rate.

\section{MATERIALS AND METHODS}

\subsection{Research design}

An observational and prospective research design were utilized in this trial.

\subsection{Research question}

Is the elevation of intra-abdominal pressure can affect the outcomes of critical patients?

\subsection{Setting}

This trial was utilized in the general ICU (16 beds) and trauma ICU (20 beds) at Assiut University Hospitals in the period between December 2015 and August 2016.

\subsection{Subjects}

A convenience sampling of 105 of both sex adults traumatized patients on the MV constituted the study sample. Cases of death during the trial (less than 72 hours) and those discharged from ICU due to a shortage of beds available in the critical setting leaked out of the trial due to insufficient measurments (number of dropped patients $=45$ ) as shown in the flow chart (see Figure 1). Then, total count of trial subjects was $105-45=60$.

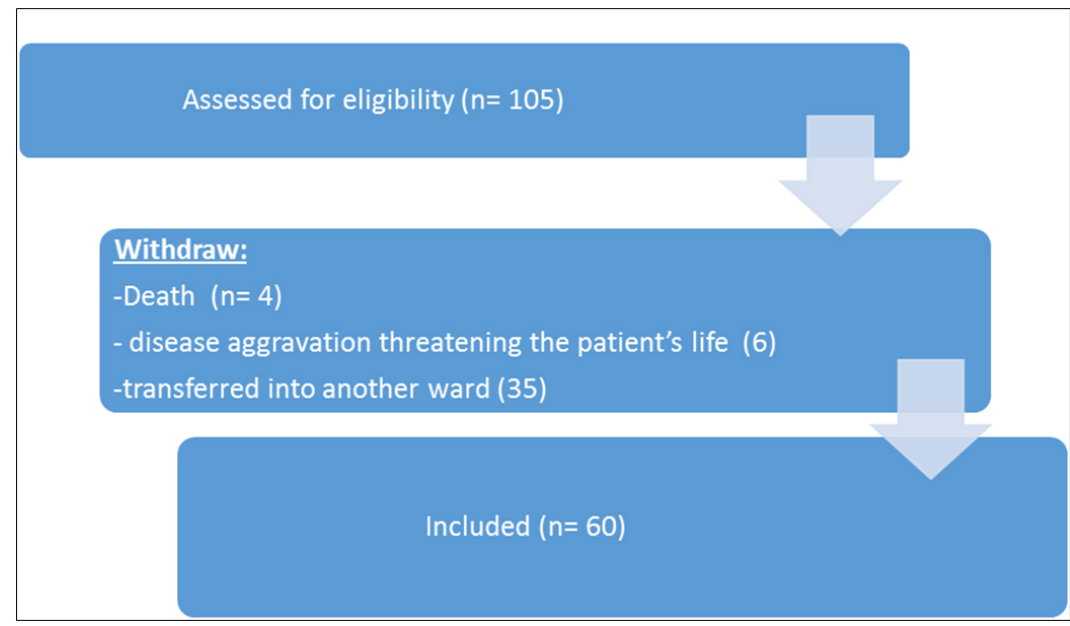

Figure 1. Flow chart of the study

The criteria included were: (1) Age $>18$ years old; (2) Patients on Mechanical ventilation; (3) Keep urine catheter in patients; (4) ICU stays $\geq 48$ hours.

The exclusion criteria were: (1) Unable to lay flat for any reason; (2) Abdominal trauma; (3) Underwent early surgical treatment primarily esophageal, gastric or bladder surgery; (4) Pregnant; (5) Morbid obesity; (6) Unlikely to survive for 24 hours.

\subsection{Tools}

Four tools were used in this study.

\section{Tool I: Patients' assessment sheet}

This sheet was designed by the principle investigator after the literature reviewing to assess patient's conditions and this sheet contained two parts.

Part one: It included patients' socio-demographic data as 
their year's old, gender and body mass index (BMI).

Part two: It included patients' clinical data as date of admission, diagnosis, date of discharge

\section{Tool II: Intra-abdominal pressure assessment instru- ment}

This instrument was developed by the principle investigator after the literature reviewing to assess patient's abdominal pressure and this tool contained two parts.

Part one: Intra-abdominal hypertension is classified into four categories; class I: IAP from 12 to $15 \mathrm{mmHg}$, class II: IAP from 16 to $20 \mathrm{mmHg}$, class III: IAP from 21 to $25 \mathrm{mmHg}$, and class IV: IAP more than $25 \mathrm{mmHg} .{ }^{[3,8]}$

Part two: It included abdominal perfusion pressure (APP = MAP - IAP. MAP is the mean arterial pressure. $)^{[4,15]}$

\section{Tool III: SOFA score assessment tool}

In 1994 Sequential Organ Failure Assessment (SOFA) scale was designed by the European Society of Critical Care Medicine (ESCCM), as a scale for measuring the conditions of acutely ill patients and incidence of failure. The score is based on 6 various scores, one each for the respiratory, cardiovascular, coagulation, and hepatic, renal and neurological systems. When the SOFA score increased during the first two days of admission in the ICU will expect a mortality rate of at least $50 \%$ up to $95 \%$. Grading yields less than 9 predictive mortality at $33 \%$ while higher than 11 can be close to or above $95 \%$. ${ }^{[15]}$

\section{Tool IV: Patients' evaluation instrument}

This instrument was developed by the principle investigator after the literature reviewing to evaluate patient's outcome as mortality, period of MV and ICU stay.

\subsection{Procedures}

Steps of measuring intra-abdominal pressure:

The IAP was measured in each patient, three measurements with 8-hour interval, at the third day of mechanical ventilator connection (Evita 4, Drager Medical, Lübeck Germany) in a pressure control mode to maintain blood gases in patients within normal range by the same investigator to avoid fluctuation between observer.

Patients were sedated to a Richmond Agitation and Sedation Scale of -5 (RASS) to be sure there are no cramps in the abdominal muscle. IAP was measured by urinary catheterization. IAP was measured in the supine position at the end of expiration after ensuring that abdominal muscle contractions were absent. The symphysis pubis was considered the reference line, and the pressure was expressed in $\mathrm{mmHg}$ (1
$\mathrm{mmHg} 1 / 41.36 \mathrm{~cm} \mathrm{H}_{2} \mathrm{O}$ ).

A pressure transducer is connected to an invasive pressure monitoring connected to three-way stopcock. Smaller than 16-gauge needle-cannula was entered into the urinary collecting tubing sampling port then the needle was disconnected. By using pressure tubing, the cannula was attached to the stopcock.

When the system is washed with saline solution and zeroing it at the point of the mid-axillary line at the iliac crest, the urinary collecting tube was clamped immediately and discharged to the sampling port. The stopcock was clamped to the patient and the pressure transducer, and $25 \mathrm{ml}$ of saline was instilled into the bladder after aspirating from the IV bag.

Then the syringe and IV tubing are clamped by the stopcock. After a fixation period of 30-60 second to allow for balance to occur, with the patient in the full reference position. After identifying IAP determination, the clamp was removed, and the amount of saline used subtracted from the patient's urinary output for that hour. ${ }^{[16]}$

\subsection{Evaluation}

The mean of IAP value was calculated as the level achieved among the measurements. Mortality, duration of MV, period of ICU acceptance and abdominal perfusion were assessed for each patient.

\subsection{Ethical consideration}

The trial approval was obtained from the faculty of nursing research ethics committee before initiating the study. The researcher clarified the purpose and aim of the trial, to patients included in the study. Oral consent was obtained from patient's care giver to ensure willingness to engage in the study. The researcher maintained anonymity and confidentiality of subjects' data. Patients were informed that they are allowed to withdraw from the study at any time without penalty.

\subsection{Statistical interpretations}

Statistical analyses were performed using SPSS 21 for windows (SPSS Inc. Chicago, USA). Values are expressed as mean and SD for continuous variable or as percentages for categorical variables. The Chi-square test or Fisher's exact test were used to compare categorical variables. Statistical significance was set at $p<.05$. Roc curve was used to test the cut-off value of IAP and mortality.

\section{RESULTS}

\subsection{Clinical profile of the studied patients}

Of the total $60 \mathrm{MV}$ patients, ten patients had normal IAP and fifty patients had IAH. Patients with normal IAP had 
mean age $54.20 \pm 4.87,80 \%$ were male, $20 \%$ with body mass index $(\mathrm{BMI})>30 \mathrm{~kg} / \mathrm{m}^{2}, 100 \%$ ranged in SOFA score from 0 to 9 , and $60 \%$ diagnosed RTA with cerebral infarction, $20 \%$ had $\mathrm{PaO}_{2} / \mathrm{FiO}_{2},<300$ and $20 \%$ managed with PEEP $>10$. As compared, patients with IAH had mean age 53.84 \pm 7.73 years, $52 \%$ were male, $24 \%$ with $\mathrm{BMI}>30 \mathrm{~kg} / \mathrm{m}^{2}$ $50 \%$ ranged in SOFA score at 16 or more, and $40 \%$ had the similar diagnosis, $32 \%$ had $\mathrm{PaO}_{2} / \mathrm{FiO}_{2},<300$ and $14 \%$ managed with PEEP $>10$. Three IAP measurements were done, that is, at morning shift as baseline, at $12 \mathrm{~h}$ and at $24 \mathrm{~h}$. From these measurements, maximal (highest in $24 \mathrm{~h}$ ) and mean IAP were recorded. Using mean IAP, the patients considered to have IAH were $50(83.33 \%)$ with mean 19.86 $\pm 4.28 \mathrm{mmHg}$ (see Table 1). Figure 2 points to the presence of strong positive correlation between mean IAP and SOFA score $\left(p\right.$ value $\left.<.001^{*}, r=.705\right)$.

Table 1. Frequency distribution of patient's characteristics and clinical data

\begin{tabular}{|c|c|c|c|c|c|c|}
\hline \multirow[t]{2}{*}{ Items } & & \multicolumn{2}{|c|}{$\begin{array}{l}\text { Patients with normal IAP } \\
(\mathrm{n}=10)\end{array}$} & \multicolumn{2}{|c|}{$\begin{array}{l}\text { Patients with IAH } \\
(n=50)\end{array}$} & \multirow[t]{2}{*}{$p$ value } \\
\hline & & $\mathbf{N}$ & $\%$ & $\mathbf{N}$ & $\%$ & \\
\hline \multicolumn{2}{|l|}{ Age (yrs.) } & \multicolumn{2}{|c|}{$54.20 \pm 4.87$} & \multicolumn{2}{|c|}{$53.84 \pm 7.73$} & .88 \\
\hline \multirow{2}{*}{ Sex } & Female & 2 & 20.0 & 24 & 48.0 & \multirow{2}{*}{.103} \\
\hline & Male & 8 & 80.0 & 26 & 52.0 & \\
\hline BMI & $>30 \mathrm{~kg} / \mathrm{m}^{2}$ & 2 & 20.0 & 12 & 24.0 & .785 \\
\hline \multirow{3}{*}{ SOFA grading } & $0-9$ & 10 & 100.0 & 13 & 26.0 & \multirow{3}{*}{.001} \\
\hline & $10-15$ & 0 & 0.0 & 12 & 24.0 & \\
\hline & $>16$ & 0 & 0.0 & 25 & 50.0 & \\
\hline \multirow{4}{*}{ Diagnosis } & Poly trauma & 1 & 10.0 & 17 & 34.0 & \multirow[t]{4}{*}{.01} \\
\hline & RTA, Cerebral infarction & 6 & 60.0 & 20 & 40.0 & \\
\hline & Diabetic Ketoacidosis & 1 & 10.0 & 6 & 12.0 & \\
\hline & ARDS & 2 & 20.0 & 7 & 14.0 & \\
\hline $\mathrm{PaO}_{2} / \mathrm{FiO}_{2}$ & $<300$ & 2 & 20.0 & 16 & 32.0 & .450 \\
\hline PEEP & $>10 \mathrm{~cm} \mathrm{H}_{2} \mathrm{O}$ & 2 & 20.0 & 7 & 14.0 & .628 \\
\hline \multirow{4}{*}{$\begin{array}{l}\text { IAP mmHg } \\
(\text { mean } \pm \text { SD) }\end{array}$} & $1^{\text {st }}$ reading & \multicolumn{2}{|c|}{$10.80 \pm 0.42$} & \multicolumn{2}{|c|}{$19.2 \pm 4.36$} & .001 \\
\hline & $2^{\text {nd }}$ reading & \multicolumn{2}{|c|}{$10.90 \pm 0.87$} & \multicolumn{2}{|c|}{$19.80 \pm 4.33$} & .001 \\
\hline & $3^{\text {rd }}$ reading & \multicolumn{2}{|c|}{$10.40 \pm 0.51$} & \multicolumn{2}{|c|}{$20.58 \pm 4.31$} & .001 \\
\hline & Mean three readings & \multicolumn{2}{|c|}{$10.70 \pm 0.39$} & \multicolumn{2}{|c|}{$19.86 \pm 4.28$} & .001 \\
\hline
\end{tabular}

Note. IAP = intra-abdominal pressure, IAH = Intra-abdominal hypertension, BMI = body mass index, ARDS = Acute respiratory distress syndrome, RTA = Rood traffic accidents, PEEP = Positive end expiratory pressure.

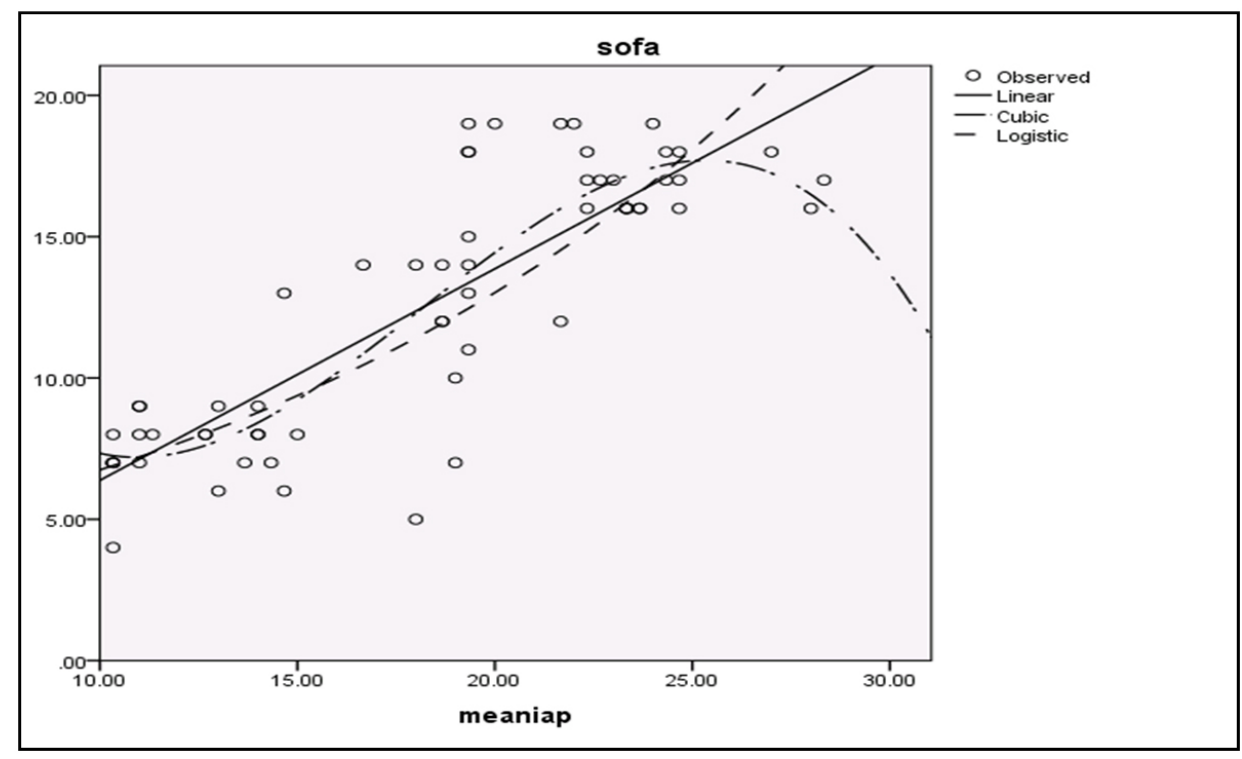

Figure 2. Correlation between mean IAP and sofa score among studied patients ( $p$ value $<.001$ and $r=.705)$ 


\subsection{Outcome of elevated IAP during ICU study period}

The study revealed that IAH deteriorated the condition of MV patients as a reduction in APP $(67.18 \pm 9.50)$, a plus MV days (14.04 \pm 10.30$)$, a plus ICU days (16.30 \pm 9.36$)$, and higher SOFA (13.66 \pm 4.35$)$, with significant differences when compared with normal IAP patients ( $p=.013, p=.035$, $p=.085, p \leq .001$ respectively) (see Table 2 ). There was a dramatic effect with increased pressure in the abdomen, Table 3 revealed that All patients at grade $4(100 \%)$ suffered from MV $>20$ days, SOFA score $>16$, ICU stays $>20$ days, and died, supported with statistical significant differences between IAH grades $(p \leq .001)$ respectively. Figure 3 clarifies that the highest percentage of IAH patients (38\% and $32 \%)$ were found at grade III (21-25), and grade II (16-20) respectively.

\subsection{ICU survival of MV patients plus IAH}

Table 4 elucidates that non-survivors $(41.67 \%)$ had a plus MV days (19.76 \pm 11.75$)$, a plus ICU days (20.80 \pm 11.22$)$, higher SOFA score (17.32 \pm 1.144$)$, and less APP (59.97 $\pm 4.14)$, and higher IAP $(23.26 \pm 2.37)$ than the survived patients $(58.33 \%)$ with statistical significant differences regarding all items $(p \leq .001)$ respectively.

Table 2. Outcomes of intra-abdominal pressure among the studied patients

\begin{tabular}{|c|c|c|c|c|c|c|c|}
\hline \multirow{2}{*}{ Items } & \multirow{2}{*}{$\begin{array}{l}\text { Patients with normal IAP } \\
(\mathrm{n}=10)\end{array}$} & \multirow{2}{*}{$\begin{array}{l}\text { Patients with IAH } \\
(n=50)\end{array}$} & \multirow{2}{*}{$p$ value } & \multirow{2}{*}{$\begin{array}{l}\text { Mean } \\
\text { difference }\end{array}$} & \multirow{2}{*}{$\begin{array}{l}\text { Std. error } \\
\text { difference }\end{array}$} & \multicolumn{2}{|l|}{$95 \%$ CI } \\
\hline & & & & & & Lower & Upper \\
\hline Age(yrs.) & $54.20 \pm 4.87$ & $53.84 \pm 7.73$ & .88 & 0.36 & 2.55 & -4.74 & 5.46 \\
\hline APP & $75.30 \pm 7.12$ & $67.18 \pm 9.50$ & .013 & 8.12 & 3.17 & 1.75 & 14.48 \\
\hline MV (days) & $6.90 \pm 2.80$ & $14.04 \pm 10.30$ & .035 & -7.14 & 3.30 & -13.75 & -0.52 \\
\hline ICU (days) & $11.00 \pm 3.77$ & $16.30 \pm 9.36$ & .085 & -5.30 & 3.03 & -11.35 & 0.75 \\
\hline SOFA & $7.40 \pm 1.42$ & $13.66 \pm 4.35$ & $<.001$ & -6.26 & 1.40 & -9.06 & -3.46 \\
\hline
\end{tabular}

Note. CI = Confidence interval, APP = Abdominal perfusion pressure

Table 3. Outcomes of different intra-abdominal hypertension grading

\begin{tabular}{|c|c|c|c|c|c|c|c|c|c|c|}
\hline \multirow{3}{*}{ Items } & & \multicolumn{8}{|c|}{ IAH $(n=50)$} & \multirow{3}{*}{$p$ value } \\
\hline & & \multicolumn{2}{|c|}{$\begin{array}{l}\text { Grade } 1 \\
(n=12)\end{array}$} & \multicolumn{2}{|c|}{$\begin{array}{l}\text { Grade } 2 \\
(n=16)\end{array}$} & \multicolumn{2}{|c|}{$\begin{array}{l}\text { Grade } 3 \\
(n=19)\end{array}$} & \multicolumn{2}{|c|}{$\begin{array}{l}\text { Grade } 4 \\
(n=3)\end{array}$} & \\
\hline & & $\mathbf{N}$ & $\%$ & $\mathbf{N}$ & $\%$ & $\mathbf{N}$ & $\%$ & $\mathbf{N}$ & $\%$ & \\
\hline \multirow{4}{*}{ MV (days) } & $<7$ & 4 & 33.3 & 4 & 25.0 & 0 & 0 & 0 & 0 & \multirow{4}{*}{$<.001$} \\
\hline & $7-14$ & 8 & 66.6 & 10 & 62.5 & 10 & 52.6 & 0 & 0 & \\
\hline & $15-20$ & 0 & 0.0 & 2 & 12.5 & 1 & 5.26 & 0 & 0 & \\
\hline & $>20$ & 0 & 0.0 & 0 & 0.0 & 8 & 42.1 & 3 & 100 & \\
\hline \multirow{3}{*}{$\begin{array}{l}\text { SOFA } \\
\text { score }\end{array}$} & $0-9$ & 11 & 91.7 & 2 & 12.5 & 0 & 0.0 & 0 & 0.0 & $<.001$ \\
\hline & $10-15$ & 1 & 8.3 & 10 & 62.5 & 1 & 5.3 & 0 & 0.0 & $<.001$ \\
\hline & $>16$ & 0 & 0.0 & 4 & 25 & 18 & 94.7 & 3 & 100 & $<.001$ \\
\hline \multirow{4}{*}{ ICU (days) } & $<7$ & 0 & 0.0 & 0 & 0.0 & 0 & 0.0 & 0 & 0.0 & \multirow{4}{*}{$<.001$} \\
\hline & $7-14$ & 10 & 83.3 & 12 & 75 & 10 & 52.6 & 0 & 0.0 & \\
\hline & $15-20$ & 2 & 16.6 & 4 & 25 & 0 & 0.0 & 0 & 0.0 & \\
\hline & $>20$ & 0 & 0.0 & 0 & 0.0 & 9 & 47.4 & 3 & 100 & \\
\hline \multirow{2}{*}{ Mortality } & Non-survivors & 0 & 0.0 & 4 & 25.0 & 18 & 94.7 & 3 & 100 & \multirow{2}{*}{$<.001$} \\
\hline & Survivors & 12 & 100 & 12 & 75.0 & 1 & 5.26 & 0 & 0.0 & \\
\hline
\end{tabular}

Using the ROC curve statistical method, we tested our mortality results against the level of intra-abdominal pressure, duration of MV and length of ICU stay to measure the sensitivity and specificity of this measurement, and hence detect the method with the best predictability for the mortality in our cases. The level below the ROC curve was measured Published by Sciedu Press for intra-abdominal pressure, duration of MV and length of ICU stay. Larger values of the test result variables indicate stronger evidence for a positive actual state (better matching). Intra-abdominal provided area under the curve of 0.988 . The cutoff point of intra-abdominal was 20.83. Duration of MV provided area under the curve of 0.887 , the cutoff point of 
MV was 12.5. Length of ICU provided area under the curve perfusion pressure among studied patients ( $p$ value $<.001$ of 0.822 , the cutoff point of the ICU was 15.5 as illustrated and $r=.45$ ) (see Figure 5).

in Figure 4. Correlation between mean IAP and abdominal

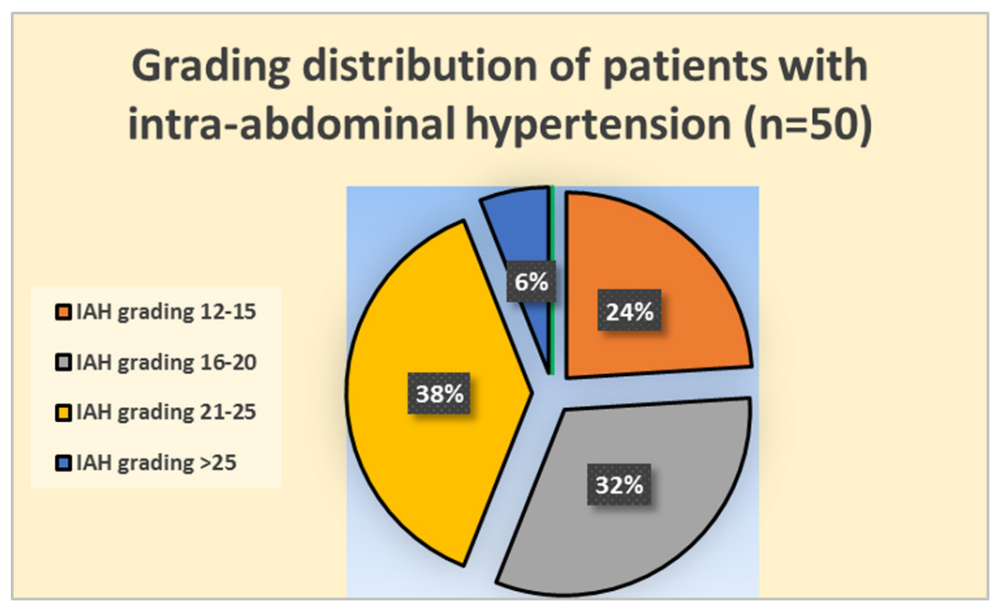

Figure 3. Intra-abdominal hypertension grading

Table 4. Comparison between survivors and non-survivors among the studied sample

\begin{tabular}{|c|c|c|c|c|c|c|c|}
\hline \multirow{2}{*}{ Items } & \multirow{2}{*}{$\begin{array}{l}\text { Survivors } \\
(\mathbf{n}=35) \\
(58.33 \%)\end{array}$} & \multirow{2}{*}{$\begin{array}{l}\text { Non-survivors } \\
(\mathrm{n}=\mathbf{2 5}) \\
(\mathbf{4 1 . 6 7 \% )}\end{array}$} & \multirow{2}{*}{$p$ value } & \multirow{2}{*}{$\begin{array}{l}\text { Mean } \\
\text { difference }\end{array}$} & \multirow{2}{*}{$\begin{array}{l}\text { Std. error } \\
\text { difference }\end{array}$} & \multicolumn{2}{|l|}{$95 \% \mathrm{CI}$} \\
\hline & & & & & & Lower & Upper \\
\hline Age(yrs.) & $52.88 \pm 7.91$ & $55.32 \pm 6.24$ & .21 & 2.43 & 1.90 & -1.37 & 6.24 \\
\hline MV (days) & $7.91 \pm 3.17$ & $19.76 \pm 11.75$ & $<.001$ & 11.84 & 2.07 & 7.68 & 16.00 \\
\hline ICU (days) & $11.57 \pm 3.41$ & $20.80 \pm 11.22$ & $<.001$ & 9.22 & 2.01 & 5.20 & 13.25 \\
\hline SOFA score & $9.25 \pm 2.93$ & $17.32 \pm 1.144$ & $<.001$ & 8.06 & 0.62 & 6.82 & 9.30 \\
\hline APP & $74.65 \pm 7.44$ & $59.97 \pm 4.14$ & $<.001$ & -14.67 & 1.64 & -17.97 & -11.38 \\
\hline IAP & $14.80 \pm 3.52$ & $23.26 \pm 2.37$ & $<.001$ & 8.45 & 0.811 & 6.83 & 10.08 \\
\hline
\end{tabular}

Note. CI = Confidence interval, APP = Abdominal perfusion pressure, IAP = Intra-abdominal pressure.

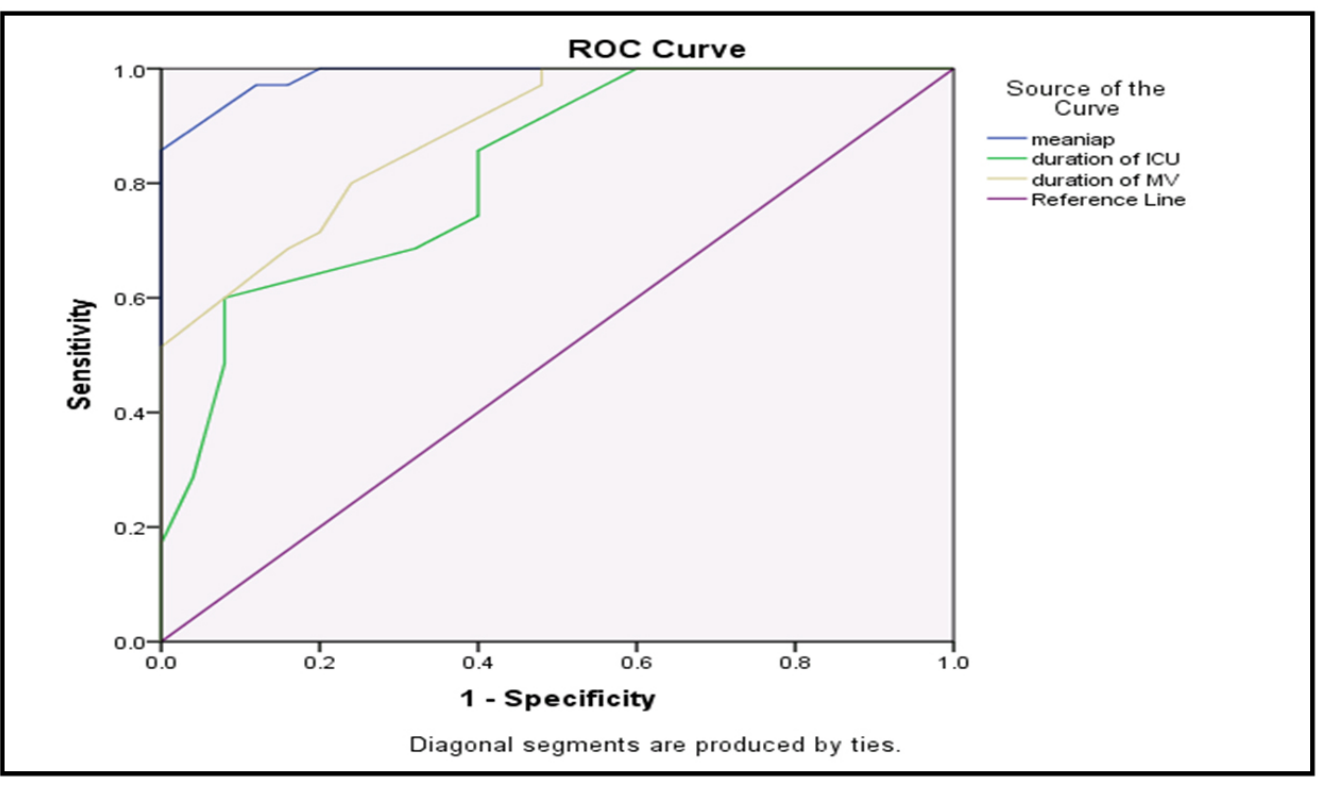

Figure 4. Roc curve for mortality results against the level of intra-abdominal, duration of MV and length of ICU stay 


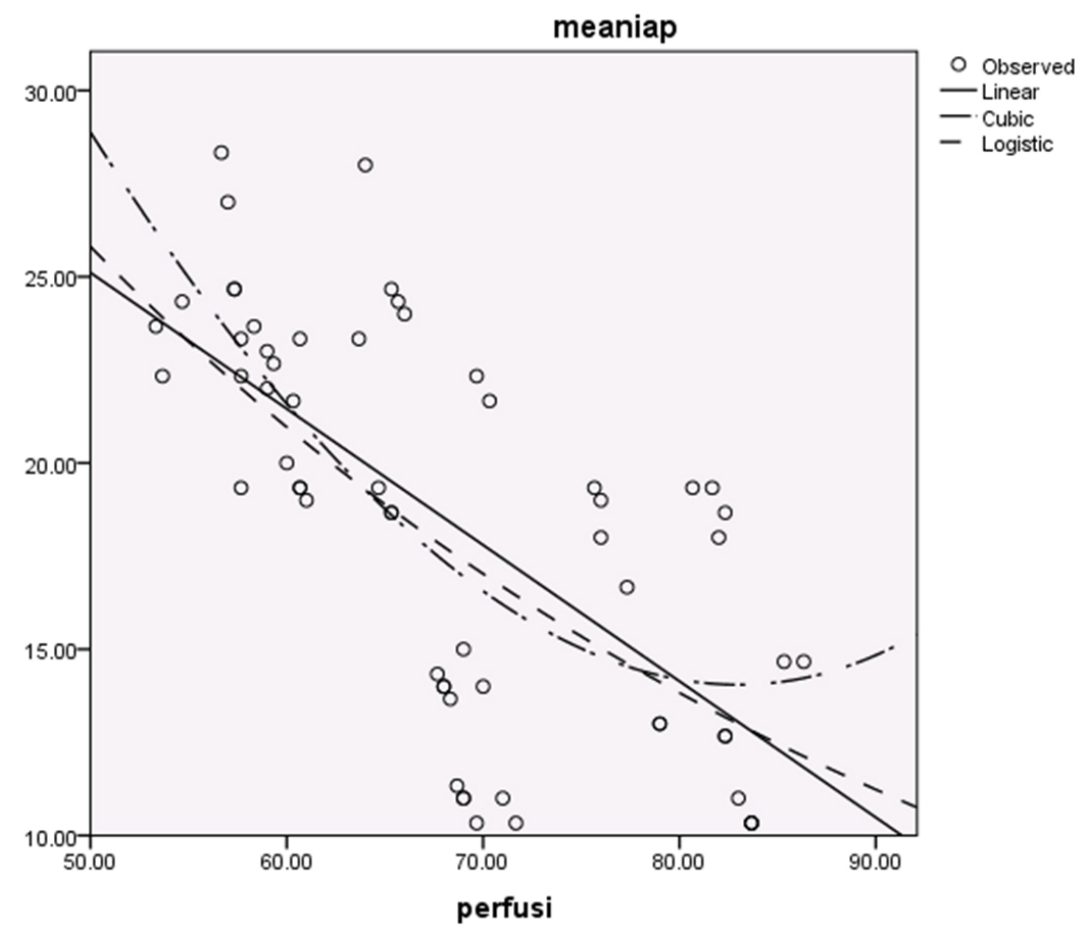

Figure 5. The correlation between mean IAP \& abdominal perfusion pressure

\section{Discussion}

IAH, over the old decade, has been increasingly recognized as a cause of morbidity and mortality in patients with serious illness coupled with severe organ dysfunction when already present in ICU acceptance and independent results are expected when developed during ICU stay. ${ }^{[17]}$

IAH occurs in approximately $50 \%$ of patients in the critical settings of general adults. ${ }^{[18]}$ The figure of this trial highlighted that there was a higher rate of IAH $(83 \%)$ and $75 \%$ of them were IAH grade II \& III. These results could be explained by that all our participants were mechanically ventilated which increase the risk for IAH. Most of the IAH patients were with BMI more than $30 \%$, which illustrate that high BMI increase the risk for IAH. It can be explained that the weight of the adipose tissue that has a direct pressure effect on the content within the abdomen. These results were consistent with the results of De Keulenaer et al. \& Kyoung \& Hong ${ }^{[19,20]}$ who found a quite high rate of IAH , in $42(91.3 \%)$ patients at $1.4 \pm 1.0$ days after ICU admission. Moreover, (Arabadzhiev, Ivanov, \& Peeva, 2014) ${ }^{[21]}$ stated that $57.5 \%$ of his patients were normal IAP and $42.5 \%$ were with IAH. Contrary to these results, in 2008, 123 patients were staying in the critical setting and screened for IAP for at least 24 hours and observed only a $30.1 \%$ rate of IAH. ${ }^{[22]}$

The PEEP program benefits are well recorded in the previous trials: as it improve gas exchange. ${ }^{[23,24]}$ So far, the use of PEEP has been aggravated IAH in this trial. This occurs as
PEEP transfer the pressure-volume curve to the right side, the added pressure subsequently directed to the abdomen. ${ }^{[25]}$ Furthermore, various trials have documented that the application of PEEP to support acute lung injury lead to reduction in visceral blood flow. ${ }^{[9]}$ Verzilii et al. $(2010)^{[26]}$ found that at a PEEP of $12 \mathrm{~cm} \mathrm{H}_{2} \mathrm{O}$ increased IAP $3.5 \mathrm{mmHg}$ from baseline $(11.7 \mathrm{mmHg})$.

Previous research has consistently shown that the elevation in the pressure within the abdomen is associated with the results of poor focused care. ${ }^{[27]}$ Furthermore, in this study it also observed a considerable increase in the period of MV and ICU stay in patients with intra-abdominal hypertension than normal IAP patients ( $p$ value $<.001^{* *}$ ). These results could be illustrated to the multiple systematic effect of intraabdominal hypertension which reduce perfusion and cardiac output for multiple system organs and affect their functions by negative way and give poor outcomes. These results were in line with Kyoung \& Hong ${ }^{[20]}$ who reported that Patients with increased IAP have longer intensive care and MV requirements than normal IAP patients $(p=.002$ and $p=.009)$ respectively and duration of ventilator support $(p=.007)$. So there were significant increases in terms of critical setting stay $(p<.001)$, mechanical ventilation period $(p<.001)$ in IAH patients rather than non IAH patients.

High abdominal pressure (AP) was identified as an independent indicator of mortality during critical illness. ${ }^{[28]}$ With regard to mortality, it was observed a dramatic rise in mortal- 
ity in patients with increased pressure within the abdomen rather than normotensive patients $\left(p=.003^{* *}\right)$. These results were consistent with Kyung and Hong ${ }^{[20]}$ who reported that the duration of IAH as an independent indicator for 60 days of death $(p=.014)$. In addition, Dalfino et al. ${ }^{[22]} \&$ Reintam et al. \& Starkopf ${ }^{[29]}$ reported a much higher medical institution death rate in patients with IAH.

Moreover, the current trial illustrated that elevated pressure within the abdomen correlate positively with high SOVA score and high mortality. This was in line with Hill et al. ${ }^{\text {27] }}$ who reported that days with elevated intra-abdominal pressure and several combined gastric symptoms were associated with the worst consecutive, SOFA score $(p=.005)$ and low perfusion pressure $(p=.001)$. The combination of elevated pressure within the abdomen and gastric signs that occur together positively correlated with the period of ICU acceptance $(p=.001)$. Days associated with elevated pressure within the abdomen along with multiple gastric signs were combined with the worst SOFA result $(p=.005)$. Critically ill who did not die had an obvious lower SOFA versus those who died 11.7 against $6.86(p=.03)$. The bad SOFA score was also dramatically increased in those who developed ACS against those who did not $(p=.0005)$. Also, severe acute pancreatitis (SAP) patients were assessed for IAH in another trial and reported high death rate, ICU acceptance period and multisystem dysfunction. ${ }^{[30]}$

The current trial illustrated that intra-abdominal pressure gave point below the curve of 0.988 . The cutoff point of intra-abdominal pressure was 20.83. Period of MV gave point below the curve of 0.887 ; the cutoff point of MV was 12.5. Length of ICU gave point below the curve of 0.822 ; the cutoff point of length of ICU was 15.5. In this regard, Sugrue Balogh \& Malbrain ${ }^{[31]}$ stated that the IAP (more than $18 \mathrm{mmHg}$ ) was an independent predictor of renal failure.

\section{Implications for critical care nursing practice}

The critical care nurse is positioned in a good place to monitor and detect changes in the circulatory and respiratory pro- files which could lead to IAH. Therefore, the considerations for nursing practice are not only to suggest that monitoring is a priority, but perhaps the focus needs to identify those at risk patients. Therefore, nurses should be aware of some of the vital changes that increase risk to develop IAH. For example,

(1) Patients on PEEP are risky to develop IAH especially if they are overweight or have another factor which may lead to fluid shifts, so IAP should be screened in these patient groups.

(2) The perfusion pressure of the abdomen should be maintained above $60 \mathrm{mmHg}$ to ensure proper perfusion of the visceral structures.

(3) Obese patients should regularly be monitored and assessed by nurse of intra-abdominal pressure as one of continuous routine assessment.

\section{Conclusions}

Nurse in acute setting is in a good position to determine the early stages of IAP increase in critical cases. Therefore the critical care nurses should monitor all patients for IAP as a routine care from the first day of admission to discharge especially overweight and high PEEP patients to early discover IAH and avoid the deteriorus effect associated with it. Also critical care nurses should provide in-service education and training for each new nurses how to measure IAP. In addition, the guidelines of management of intra-abdominal hypertension should be available in written format in critical care units and emergency units.

\section{ACKNOWLEDGEMENTS}

Many thanks to all patients who included in this trial and critical care physicians and nurses at trauma and general ICUs, in the medical institution of Assiut University for their valuable co-operation.

\section{CONFLicts OF InTEREST Disclosure}

No conflict of interest was reported by all authors.

\section{REFERENCES}

[1] Bond L, Hallmark B. Educating Nurses in the Intensive Care Unit About Gastrointestinal Complications: Using an Algorithm Embedded into Simulation. Critical Care Nursing Clinics of North America 2017.

[2] De Keulenaer B, De Waele J, Powell B, et al. What is normal intraabdominal pressure and how is it affected by positioning, body mass and positive end-expiratory pressure? Applied Physiology in Intensive Care Medicine. 2012; 2: 219-226.

[3] Christensen M, Judy Craft. The cardio-respiratory effects of intra- abdominal hypertension: Considerations for critical care nursing practice. Intensive and Critical Care Nursing. 2018; 44: 53-58. PMid:28600109 https://doi.org/10.1016/j.iccn.2017.05 .003

[4] Andrew WK, Derek JR, Jan DW, et al. Intra-abdominal hypertension and the abdominal compartment syndrome: Updated consensus definitions and clinical practice guidelines from the World Society of the Abdominal Compartment Syndrome. Intensive Care Medicine. 2013; 39: 1190-1206. PMid:23673399 https ://doi .org/10.1007/s0 0134-013-2906-z 
[5] Hernandez H, Thomas JAG, Solis HT, et al. The impact of surgery on mortality and morbidity in patients with severe acute pancreatitis and intra-abdominal hypertension. Cogent Medicine. 2017; 4: 134007.

[6] Inal MT, Memis D, Sezer YA, et al. Effects of intra-abdominal pressure on liver function assessed with the LiMON in critically ill patients. Canadian Journal of Surgery. 2011; 54(3): 161. PMid:21443832 https://doi.org/10.1503/cjs.042709

[7] Newcombe J, Mathur M, Ejike JC. Abdominal compartment syndrome in children. Critical Care Nurse. 2012; 32(6): 51-61. PMid:23203955 https://doi.org/10.4037/ccn2012761

[8] Hunt L, Frost SA, Newton PJ, et al. A survey of critical care nurses' knowledge of intra-abdominal hypertension and abdominal compartment syndrome. Australian Critical Care. 2017; 30(1): 21-27. PMid:27036928 https://doi.org/10.1016/j . aucc. 2016.02 .001

[9] Morejon C, Barbeito T. Effect of mechanical ventilation on intraabdominal pressure in cirically ill patients without other risk factors for abdominal hypertension: and observational mulitcenter epidemiological study. Ann. Intensive Care. 2012.

[10] Liang YJ, Huang HM, Yang HL, et al. Controlled peritoneal drainage improves survival in children with abdominal compartment syndrome. Italian Journal of Pediatrics. 2015; 41(1): 29. PMid:25881886 https://doi .org/10.1186/s13052-015-0134-6

[11] Kim IB, Prowle J, Baldwin I, et al. Incidence, risk factors and outcome associations of intra-abdominal hypertension in critically ill patients. Anaesthesia and Intensive Care. 2012; 40(1): 79.

[12] Lee RK. Intra-abdominal hypertension and abdominal compartment syndrome a comprehensive overview. Critical Care Nurse. 2012; 32(1): 19-31. PMid:22298715 https ://doi .org/10.4037/ccn2 012662

[13] De Waele JJ, Malbrain ML, Kirkpatrick AW. The abdominal compartment syndrome: evolving concepts and future directions. Critical Care. 2015; 19(1): 211. PMid:25943575 https://doi.org/10.1 186/s13054-015-0879-8

[14] Hunt L, Frost SA, Hillman K, et al. Management of intraabdominal hypertension and abdominal compartment syndrome: a review. Journal of Trauma Management Outcomes. 2014; 8(1): 2. PMid:24499574 https://doi .org/10.1186/1752-2897-8-2

[15] Lee RK. The effects of nursing activities on the intra-abdominal pressure of patients at risk for intra-abdominal hypertension. Anaesthesiology Intensive Therapy. 2017; 49(2): 116-121. PMid:28502072 https://doi.org/10.5603/AIT.a2017.0020

[16] Kirkpatrick A, Roberts D, De Waele J, et al. Pediatric Guidelines Sub-Committee for the World Society of the Abdominal Compartment Syndrome. Intra-abdominal hypertension and the abdominal compartment syndrome: updated consensus definitions and clinical practice guidelines from the World Society of the Abdominal Compartment Syndrome. Intensive Care Med. 2013; 39(7): 1190-1206. PMid:23673399 https ://doi .org/10.1007/s00134-013-290 6-z

[17] Dalfino L, Sicolo A, Paparella D, et al. Intra-abdominal hypertension in cardiac surgery. Interactive Cardiovascular and Thoracic Surgery. 2013; 17(4): 644-651. PMid:23820668 https://doi.org/10.1 093/icvts/ivt272
[18] Chen YZ, Yan SY, Chen YQ, et al. Noninvasive monitoring of intraabdominal pressure by measuring abdominal wall tension. World Journal of Emergency Medicine. 2015; 6(2): 137. PMid:26056545 ht tps://doi.org/10.5847/wjem.j .1920-8642.2015.02.009

[19] De Keulenaer BL, De Waale JJ, Powell B, et al. What is normal intraabdominal pressure and how is it affected by positioning body mass and positive end-expiratory pressure? Intensive Care Med. 2009; 35(6): 969-976. PMid:19242675 https://doi .org/10.1007/s0 0134-009-1445-0

[20] Kyoung KH, Hong SK. The duration of intra-abdominal hypertension strongly predicts outcomes for the critically ill surgical patients: a prospective observational study. World Journal of Emergency Surgery. 2015; 10(1): 22. PMid:26056530 https://doi .org/10.1186/s1 3017-015-0016-7

[21] Arabadzhiev G, Ivanov V, Peeva K. INTRA-ABDOMINAL HYPERTENSION AND SECONDARY ABDOMINAL COMPARTMENT SYNDROME IN MEDICAL PATIENTS-COMPLICATION WITH A HIGH MORTALITY. Trakia Journal of Sciences. 2014; 12(1): 202-207.

[22] Dalfino L, Tullo L, Donadio I, et al. Intra-abdominal hypertensionand acute renal failurein critically ill patients. Intensive Care Medicine. 2008; 34(4): 707-713. PMid:18157662 https://doi .org/10.1 007/s00134-007-0969-4

[23] Gattinoni L, Carlesso E, Brazzi L, et al. Positive end expiratory pressure. Curr. Opin. Crit. Care. 2010; 16(1): 39-44.

[24] Sundaresan A, Chase JG. Positive end expiratory pressure in patients withacute respiratory distress syndrome-the past, present and future. Biomed. Signal Process. Control. 2012; 7(2): 93-103. https://doi.org/10.1016/j.bspc.2011.03.001

[25] Malbrain M, De Waele J. Intra-abdominal Hypertension. Cambridge: Cambridge Univer-sity Press; 2013.

[26] Verzilii D, Constantin JM, Sebbane M, et al. Positive end expiratory pressure effects the value ofintra-abdomnal pressure in acute lung injury/acute respiratory distress syn-drome patients: a pilot study. Crit. Care. 2010; 14(4): 137-142.

[27] Hill L, Hill B, Miller M, et al. The effect of intra-abdominal hypertension on gastro-intestinal function. Southern African Journal of Critical Care. 2011; 27(1): 12-19.

[28] Cheatham ML, Safcsak K. Is the evolving management of intraabdominal hypertension and abdominal compartment syndrome improving survival? Critical Care Medicine. 2010; 38(2): 402-407. https://doi.org/10.1097/CCM. 0b013e3181b9e9b1

[29] Reintam BA, Parm P, Kitus R, et al. Risk factors for intra-abdominal hypertension in mechanically ventilated patients. Acta Anaesthesiologica Scandinavica. 2011; 55: 607-614. PMid:21418151 https: //doi.org/10.1111/j.1399-6576.2011.02415.x

[30] Ke L, Ni HB, Sun JK, et al. Risk factors and outcome of intraabdominal hypertension in patients with severe acute pancreatitis. World Journal of Surgery. 2012; 36: 171-178. PMid:21964817 https://doi.org/10.1007/s00268-011-1295-0

[31] Sugrue M, Balogh Z, Malbrain M. Intra-abdominal hypertension and renal failure. ANZ Journal of Surgery. 2004; 74(1-2): 78-78. https://doi.org/10.1046/j.1445-1433.2003.02896.x 